\title{
Anatomical and Radiographic Study on the Skull and Mandible of the African Lion (Panthera leo)
}

\author{
Reda Mohamed ${ }^{1,2}$ \\ 1 Department of Basic Veterinary Sciences, School of Veterinary \\ Medicine, Faculty of Medical Sciences, The University of the West \\ Indies, St. Augustine Campus, St. Augustine, Trinidad and Tobago \\ ${ }^{2}$ Anatomy and Embryology Department, Faculty of Veterinary \\ Medicine, Beni-Suef University, Beni-Suef, Egypt
}

\begin{abstract}
Address for correspondence Reda Mohamed, PhD, Department of Basic Veterinary Sciences, School of Veterinary Medicine, Faculty of Medical Sciences, The University of the West Indies, St. Augustine Campus, St. Augustine, Trinidad and Tobago

(e-mail: reda.mohamed@sta.uwi.edu).
\end{abstract}

J Morphol Sci 2019;36:174-181.

\begin{abstract}
Keywords

- anatomy

- radiography

- skull

- mandible

- lion

Objective The taxonomic affiliations can be detected via the skull morphology. The objective of this study was to give a detailed gross anatomical and radiographic description of the bones and foramina of the skull and mandible of the lion. This information could be used in the identification of the skull and mandible of the lion, which is of great importance in taxonomic affiliation and to help the zoo veterinarians to detect, diagnose, and treat head conditions.

Materials and Methods The current work was conducted on two skulls and mandibles of lions. The skulls and mandible were prepared using standard boiling and maceration technique. The gross and radiographic photos of the bones and foramina of the skull and mandible were taken using a Kodak digital camera and Siemens mobile full wave X-ray machine (Siemens Medical Solutions, Erlangen, Germany).

Results The skull of the lion comprised of facial and cranial parts. The nasal openings were large, and the bony orbit was incomplete. The supraorbital foramen was absent. The zygomatic arch was large. The frontal region had a deep longitudinal depression dorsally. The mandible was a paired bone with movable articulation, and it had strongly excavated masseteric fossa with a well-developed crest. The dental formula was 30 teeth consisting of small incisors, long canines and carnassial premolars.

Conclusion The current study showed that the osteology and foramina of the skull and mandible of the lion were similar to those of other mammals. The information is important for taxonomic affiliation, and wildlife forensic as well as to help the zoo veterinarians to manage clinical head diseases in this species.
\end{abstract}

\section{Introduction}

The lion is part of the Felidae family, and one of the four large cats of the Panthera species, along with the tiger, panther, and wild leopard. Europe, Asia, the Middle East, and large parts of Africa were once the main regions of habitat for the lion (Panthera leo). ${ }^{1,2}$ Now, they are mostly found in savannah and grasslands throughout sub-Saharan Africa, while many are

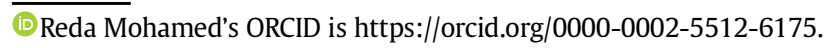

kept in zoos throughout the world. ${ }^{3}$ Over the years, there were reports of abnormalities in the skulls of the lions at these zoogardens of Europe, ${ }^{4}$ South Africa, ${ }^{5}$ Australia, ${ }^{6}$ the United States, ${ }^{7}$ and Asia. ${ }^{8}$ The skull forms the head skeleton, which protects the brain and organs of special sense, such as the eyes, ears and nose, besides housing teeth for mastication. The head is important in body coordination and defense as well as olfaction and deglutition. ${ }^{9}$ The skull of an animal contributes to the phylogenetic structure of the head of animal species, as received

January 15, 2019

accepted

April 14, 2019
DOI https://doi.org/

10.1055/s-0039-1691756. ISSN 2177-0298.
Copyright (e) 2019 by Thieme Revinter

Publicações Ltda, Rio de Janeiro, Brazil
License terms

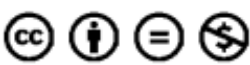


seen in the feline or in the camel. ${ }^{10}$ Further, the morphology of the skull gives rise to the animal's taxonomic affiliations, ${ }^{11,12}$ and the occipital bone of the skull can be used in forensic medicine to determine its gender. ${ }^{13}$ The foramen magnum of the skull has scientific importance due to its clinical and variant morphological importance, ${ }^{14}$ and any deviation in its form and structure can lead to neurological indications. ${ }^{15}$ There are no available literatures describing the osteology of the skull and mandible of the lion. Thus, the main purpose of this article is to give a detailed description of the gross anatomy of the bones and foramina of the lion's skull and mandible. This description would be useful in the identification of the skull and mandible of the lion, as well as to help the zoo veterinarians in the detection, diagnosis, and treatment of head affections in this species.

\section{Materials and Methods}

The heads of two lions that died in the zoo in Trinidad and Tobago were brought to the department of basic veterinary sciences, School of Veterinary Medicine, Faculty of Medical Sciences, University of the West Indies, Trinidad and Tobago. No skeletal deformities were detected upon inspection of the heads, which were then boiled and treated to remove the skin and muscles, then bleached in 3\% hydrogen peroxide and then left to dry. ${ }^{16}$ The different standard views of the skull and mandible were then photographed, followed by radiographic photography taken for documentation using a Kodak digital camera and Siemens mobile full wave X-ray machine (Siemens Medical Solutions, Erlangen, Germany), respectively. The bones and foramina of the skull were named according to Nomina Anatomica Veterinaria. ${ }^{17}$

\section{Results}

\section{The Bones and Foramina of the Facial Region}

The facial part of the skull of the lion was relatively large and compressed laterally. The bony part of the dorsal, lateral and medial aspect of the face was made up of the nasal, premaxilla, lacrimal, zygomatic, maxilla, palatine, pterygoid, vomer and turbinate bones. In the ventral part of the skull, the hard palate was observed and was made up of the palatine processes of the premaxilla and palatine bones. It appeared as V-shaped at its caudal margin. In the ventral view, the choanae were seen at the terminal part of the hard palate, and the cribriform plate served to separate the nasal cavity from each of the cranium.

The nasal bones were paired, and flattened and triangular in shape in the nasal cavity. They articulated with the frontal, maxillary and incisive bones, and their oral end was comma shaped. The nasal bones were free from notches and foramina. A deep longitudinal depression was seen in the dorsal aspect of the nasal bones. The caudal projection of the nasalfrontal suture extended more caudal than that of the maxillary-frontal suture. The lateral and ventral walls of the nasal cavity were formed by the premaxillae or incisive bones, which were paired and rounded. Each of the premaxilla bones had less developed nasal and palatine processes. In the rostral portion of each premaxilla, the alveoli for the three upper incisors were observed along with a welldefined space for the lower canine tooth frame (-Figs. 1-3).

The cranial rim of the orbit of the lion was bounded by the lacrimal bones, which articulated with the zygomatic, maxillary and frontal bones. They presented the lacrimal segment only, and they also presented the orifice of the nasolacrimal duct. The zygomatic bones were well developed with a quadrilateral shape, and they had the frontal processes, which, with the well-developed zygomatic processes of the frontal bones, tended to close the orbital arches. They had the temporal processes, which contributed to form the massive zygomatic arch with zygomatic processes of the temporal bones ( - Fig. 1).

The maxillae were the most developed and largest bones in the face. They were attached to the premaxilla, nasal, lacrimal and frontal bones, and formed the wall of the hard palate. The dental edges of the maxillary bones presented the dental alveoli for one canine, three premolars, and one molar. The paired palatine bones were observed in the palate and orbit and circumscribing the choanae. They had the perpendicular and horizontal processes. The horizontal process and the palatine process of the maxilla formed the oral palatine foramen. The pterygoid bones were delicate bones, which had a very developed hamulus in their caudal aspect. They formed the roof and lateral walls of the nasopharyngeal passage, while the vomer bone was an elongated, thin unpaired bone, which contributed to the nasal cavity cranially and articulated with the premaxilla, presphenoid and maxilla bones. In the nasal cavity, the turbinate bones were attached to its lateral walls as delicate, scroll-like, complex bony plates. The foramina of the facial region of the skull were the large infra-orbital foramen representing the maxillo-incisive or infraorbital canal opening, the sphenopalatine foramen, the oral palatine fissures, the orifice of the nasolacrimal duct and the choanae (-Figs. 1-3).

\section{The Bones and Foramina of the Cranial Region}

The cranium was moderately compressed latero-medially and slightly flattened dorsoventrally in the fronto-orbital region. The frontal, parietal, temporal, basioccipital, basisphenoid, and presphenoid bones formed the bony part of the dorsal, lateral, ventral, and caudal aspects the basicranial region in the lion. The frontal bone formed the roof of the skull and contributed to the temporal fossae and orbital cavities. It had the short zygomatic processes with neither supraorbital groove nor foramen, and it attached to the nasal bones cranially. A deep longitudinal depression was seen in the frontal region. The bulk of the roof of the skull was formed by the parietal bones, which had a less prominent temporal line and a well-developed external sagittal crest. The presphenoid bone was seen in the nasopharyngeal passage as a single bone and consisted of a body and two orbital wings. The basisphenoid bone was a single bone between the presphenoid bones and the basilar part of occipital bone and it consisted of a body, two wings. The nuchal crest of the occipital bone was prominent, angular and directed caudally. The median occipital crest was thick and more prominent in its proximal part. The tympanic bulla was large, while the mastoid process and jugular processes were small, and the muscular tubercle was not prominent. The 

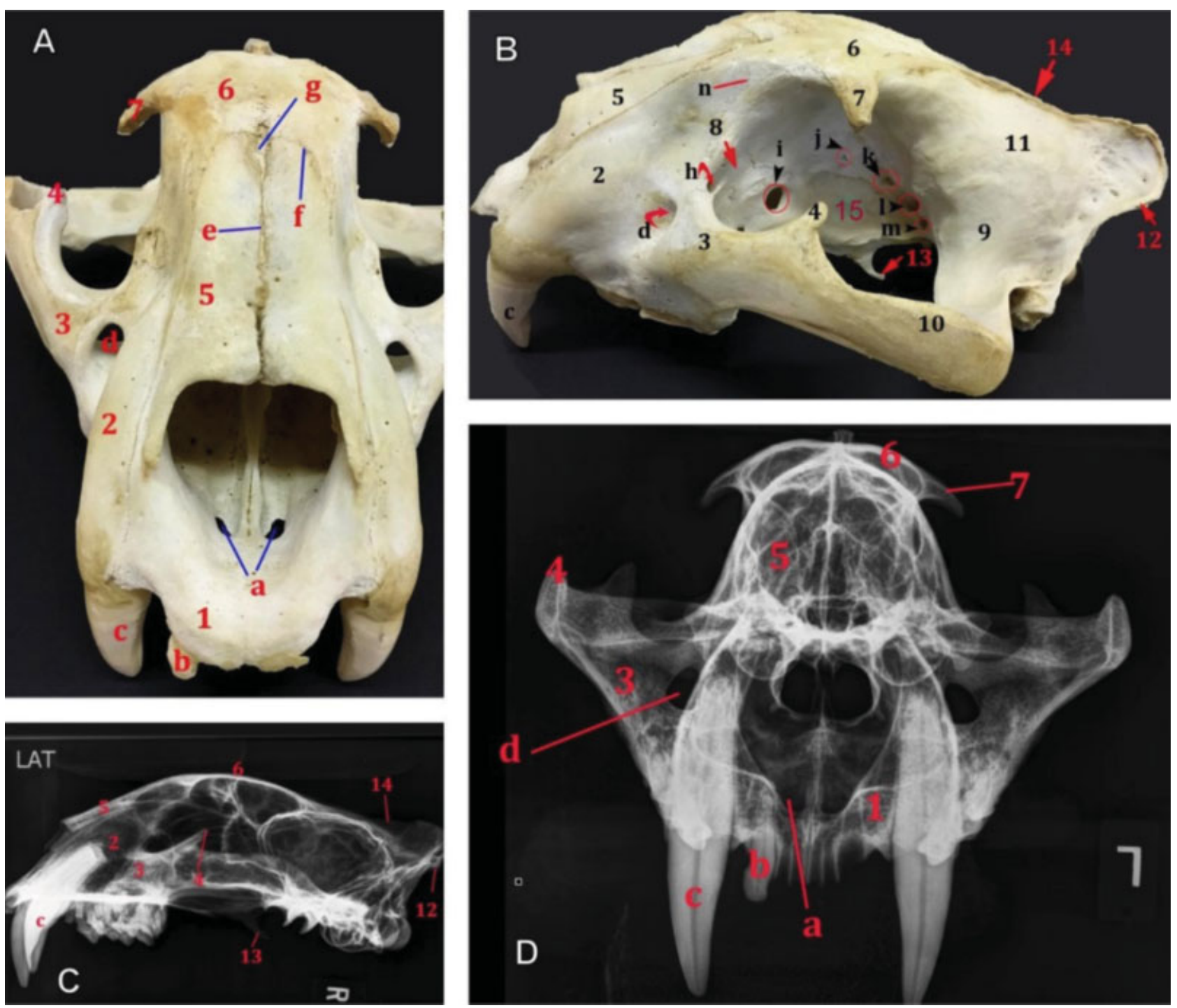

Fig. 1 Gross and radiographic images showing the rostral (A-D) and lateral (B-C) aspects of the skull of the African lion. 1-Premaxilla bone; 2-Maxilla bone; 3-Zygomatic bone; 4-Frontal process of zygomatic bone; 5-Nasal bone; 6-Frontal bone; 7-Zygomatic process of frontal bone; 8-Lacrimal bone; 9-Temporal bone; 10-Zygomatic process of temporal bone; 11-Parietal bone; 12-Nuchal crest; 13-Hamulus of pterygoid bone; 14-External sagittal crest; 15-Pterygoid bone; a- Palatine fissures; b-Upper incisor; c-Upper canine; d-Infraorbital foramen; e-Internasal suture; $\mathrm{f}$ - Nasofrontal suture; $\mathrm{g}$-A longitudinal dorsal depression in the nasal and frontal bones; h-Orifice of the nasolacrimal duct; i-Sphenopalatine foramen; $j$-Ethmoidal foramen; $k$-Optic foramen; I- Foramen orbitorotundum; m-Alar foramen; n-Frontomaxillary suture.

basilar tubercles were not observed. The temporal bones contributed to the glenoid cavity, the brain case and the zygomatic arch by its zygomatic process. The intraparietal bone was not seen externally, as it was merged with the parietal bone to form the highest caudal part of the external sagittal crest. The temporomandibular joint of the lion was formed between the coronoid process of the mandible and the glenoid fossa of the skull. The foramina of the basicranial region were the external and internal acoustic meatuses and foramen magnum, foramen lacerum, and hypoglossal canal in the condyloid fossa. The foramina of the pterygopalatine fossa at the caudal aspect of the orbit on the wing of the presphenoid includes the ethmoidal, optic, orbitorotundum, rostral alar, and oval foramina, in addition to the caudal alar and jugular foramina. The ethmoidal fossa was deep with extensive cribriform plate and the frontal sinus was observed only in the frontal bone. Moreover, the hypophyseal fossa was prominent within the cranium on the dorsal surface of the basisphenoid bone (-Figs. 1-4).

\section{The Mandible and Its Foramina}

The mandible was the largest paired bone of the head region of the lion, in which the right and left portions were fused rostrally at the mandibular symphysis. The joint formed was fibrocartilaginous and not ossified. Each part of the mandible consisted of a body and a ramus. The ramus had coronoid, condylar and angular processes along with the masseteric and pterygoid fossae. The condylar process was directed ventrally, and it articulated with the glenoid cavity of the skull at the temporomandibular joint. The coronoid process was a well-developed large process directed slightly caudally, forming the dorsal part of the ramus. The angular process directed caudo-medially. The 

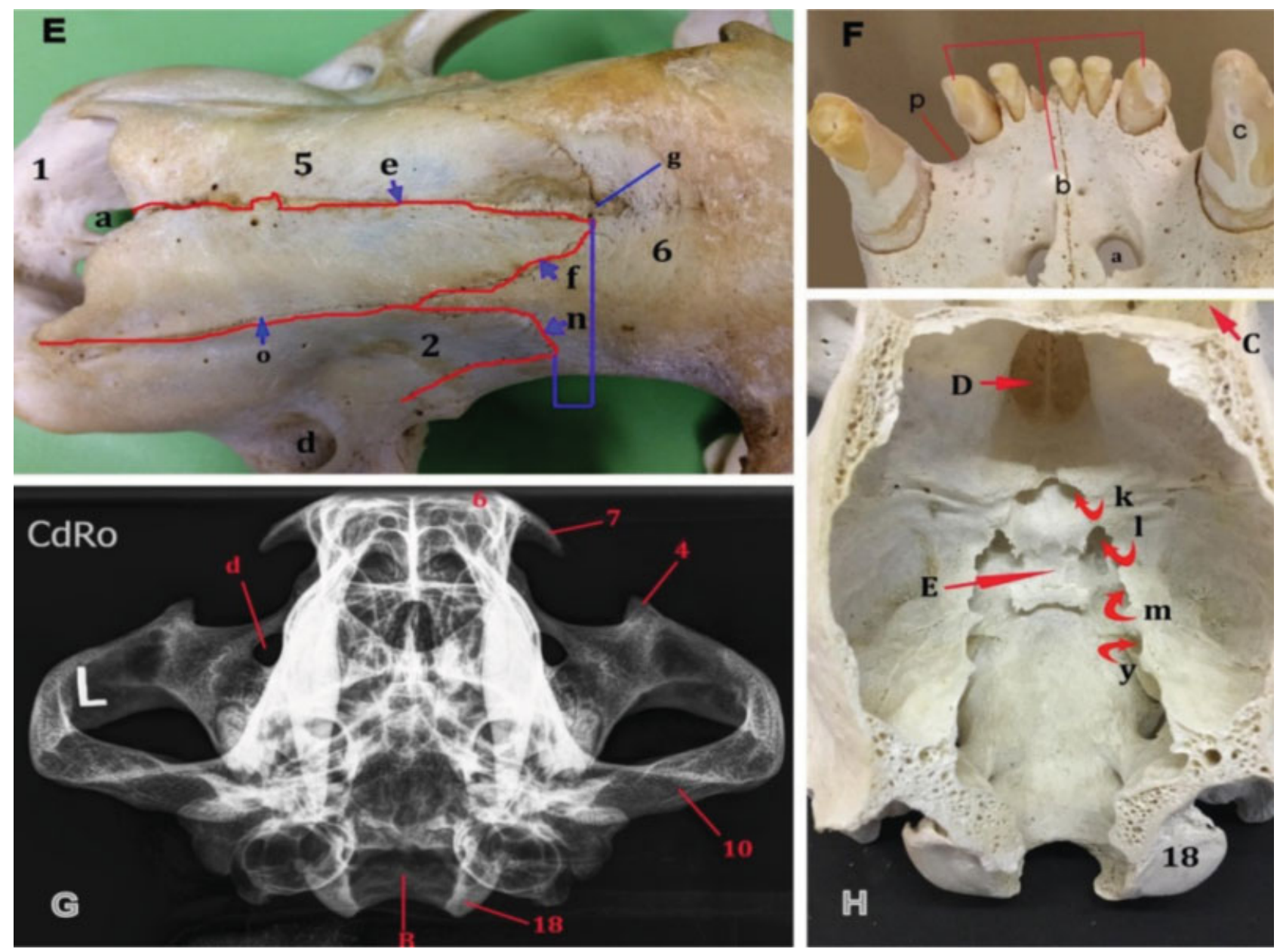

Fig. 2 Gross photos of the rostral aspect (E-F); Radiography of the caudorostral aspect (G) and cranium of the skull of the African lion (H). 1-Premaxilla bone; 2-Maxilla bone; 4-Frontal process of zygomatic bone; 6-Frontal bone; 7-Zygomatic process of frontal bone; 18-Occipital condyle; a- Palatine fissures; b-Upper incisors; c-Upper canine; d-Infraorbital foramen; e-Internasal suture; f-Nasofrontal suture; $\mathrm{g}$-A longitudinal dorsal depression in the nasal and frontal bones; n-Frontomaxillary suture; o-Nasomaxillary suture; p-A groove for lower canine tooth; k-Optic foramen; I-Foramen orbitorotundum; m-Alar foramen; y-Oval foramen; B-Foramen magnum; C-Frontal sinus; D-Cribriform plate; E-Hypophyseal fossa.

ramus of the mandible has the strongly excavated masseteric fossa with a well-developed crest located on its lateral surface and the pterygoid fossa, which was smooth and presented the mandibular foramen on the medial surface of the ramus. The dorsal border of the mandible housed the dental alveoli for three lower incisors, one canine, two premolars and one molar. The diastema was observed as the space between the lower incisors and premolars. There were two mandibular foramina on the two rami of the mandible on the pterygoid fossae, near the angular processes, while there were two mental foramina on each side of the body of the mandible laterally ( - Fig. 4). The dental formula of the lion was 30 teeth; Incisor (I) $3 / 3$, canines (C) $1 / 1$, premolars $(\mathrm{Pm}) 3 / 2$, molar $(\mathrm{M}) 1 / 1 \times 2=30$.

\section{Discussion}

There was no available literature on the osteology of the skull and mandible of the African lion, except the comparative splanchnocranium study between the brown bear and lion. ${ }^{1}$ The present results, as well as those in bears, lions, ${ }^{1}$ tigers, ${ }^{18}$ horses, ${ }^{19}$ blackbucks, ${ }^{20}$ and in dogs, ${ }^{21}$ stated that the nasal bone was articulated cranially with the incisive bone, while it also articulates with the lacrimal bone in camels ${ }^{22}$ and in oxen. ${ }^{23}$ Moreover, the caudal projection of the nasal-frontal suture extended more caudal than that of the maxillaryfrontal suture; a similar result was mentioned in tigers, ${ }^{24}$ while the same author stated that the two caudal projections of the two sutures were a line together in lions.

The premaxilla of the lion was very thick and had three dental alveoli for the upper incisor teeth; a similar result was mentioned in bears, in lions, ${ }^{1}$ and in tigers, ${ }^{18}$ while it has no alveoli in blackbucks, ${ }^{20}$ and in oxen. ${ }^{23}$ Moreover, it had a well-defined space for the lower canine tooth frame in the lion. ${ }^{1}$ The palatine process of the premaxilla shared in the formation of the bony hard palate in the lion, as mentioned in blackbucks ${ }^{20}$ and in oxen. ${ }^{23}$ Furthermore, the palatine fissures were rounded in lion; a similar result was recorded in the same animal, while they were oval in bears and in lions. ${ }^{1}$

The lacrimal bone of the lion presented the lacrimal segment only, and it also presented the orifice of the nasolacrimal duct; a similar result is noticed in lions and brown bears, 1,25 while the lacrimal bone is composed of a facial and a lacrimal 

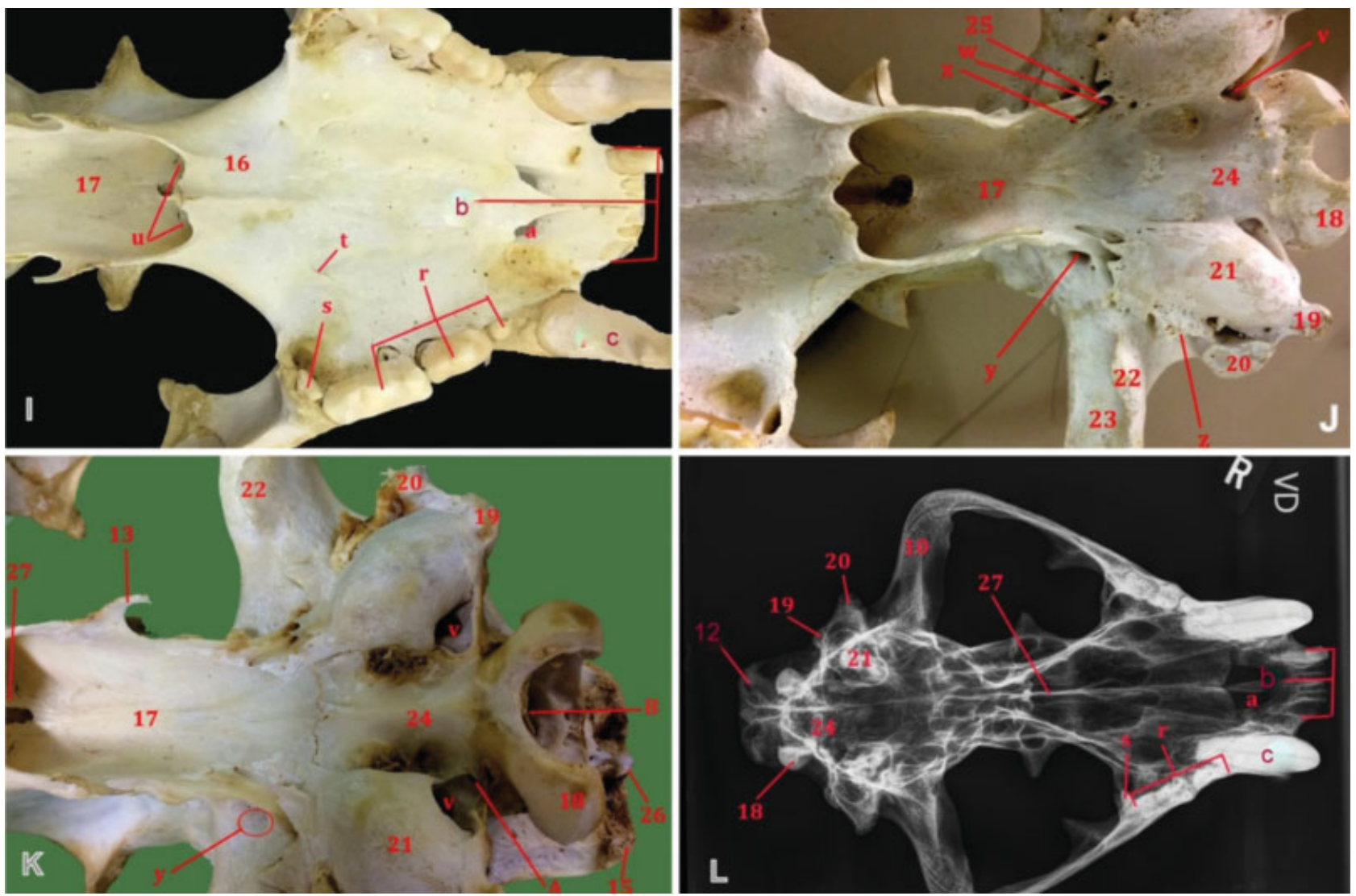

Fig. 3 Gross and radiographic images (I-L) showing the ventral aspect of the skull of the African lion. 10-Zygomatic process of temporal bone; 12-Nuchal crest; 13-Hamulus of pterygoid bone; 16-Horizontal part of palatine bone; 17-Presphenoid bone; 18-Occipital condyle; 19-Jugular process; 20-Mastoid process; 21-Tympanic bulla; 22-Retroglenoid process; 23-Mandibular fossa; 24- Basioccipital bone; 25-Muscular process; 26-External occipital protuberance; 27-Vomer bone; (18); a-Palatine fissures; b-Upper incisor; c-Upper canine; r-upper premolars; s-Upper molar; t-Major palatine foramen; v-Jugular foramen; w-Foramen lacerum; $x$-Caudal alar foramen; $y$-Oval foramen; z-External acoustic meatus; A-Hypoglossal canal; B-Foramen magnum.

part that fuse together in horses, ${ }^{19}$ in blackbucks, ${ }^{26}$ and in oxen. ${ }^{23}$ However, the lacrimal bone of sambar deer is marked by a very prominent depression for infraorbital gland. ${ }^{27}$

The zygomatic bone of the lion was well developed, and its frontal processes did not articulate with the zygomatic process of the frontal bone; a similar result was mentioned in bears and lions. ${ }^{1}$ The latter articulation is present in blackbucks, ${ }^{26}$ and in oxen. ${ }^{23}$ On the other hand, the zygomatic bone is absent in tigers. ${ }^{18}$ Moreover, the zygomatic arch was very large with distinct ridges for masseter in lion as mentioned in the same animal. ${ }^{28}$ On the other hand, the zygomatic process of frontal is absent in rhinoceros. ${ }^{29}$

The maxilla of the lion was the most developed massive bone in the face, with neither facial crest nor facial tuberosity; a similar result was mentioned in tigers, ${ }^{18}$ in $\operatorname{dogs}^{20}$ and in leopard cats. ${ }^{26}$ However, the facial crest and tuberosity are present in blackbucks, ${ }^{20}$ and in oxen, ${ }^{23}$ while horses have the facial crest only. ${ }^{19}$ Moreover, the maxilla of camel lacks the maxillary tuberosity and facial crest. ${ }^{30}$ Furthermore, the maxilla had the dental alveoli for one canine, three premolars, and one molar in the lion, while the maxilla has one canine, one vestigial tooth, one premolar and one molar in lions, and one canine, one vestigial tooth, two premolars and one molar in bears. ${ }^{1}$
The frontal bone formed the roof of the skull, and it had the zygomatic processes and was characterized by the presence of a deep longitudinal depression, while the external surface of the frontal bone is smooth in brown bears. ${ }^{25}$ Moreover, the supraorbital foramen was absent in the lion; a similar result was mentioned in tigers, ${ }^{18,31}$ in dogs, ${ }^{21}$ in adult sloth bears, ${ }^{32}$ in arctic foxes, ${ }^{33}$ and in common opossum. ${ }^{34}$ The supraorbital foramen is present in blackbucks, ${ }^{20}$ and in oxen. ${ }^{23}$ There are two to three in number in Sambar deer. ${ }^{27}$ The frontal sinus was observed only in the frontal bone of the lion; a similar result was mentioned in horses, ${ }^{19}$ in tigers, ${ }^{31}$ and in small ruminants. ${ }^{35}$ However, the frontal sinus of oxen occupies parts of the occipital, temporal, parietal and interparietal bones. ${ }^{35}$

The bulk of the roof of the skull of the lions was formed by the parietal bones, which had a well-developed sagittal crest. However, these bones do not form part of the cranial cavity roof but form a part of the caudal wall of the cranium dorsally in blackbucks, ${ }^{20}$ and in oxen. ${ }^{23}$

The orbital and round foramina were united to form the foramen orbitorotundum in lions; similar results were mentioned in blackbucks, ${ }^{20}$ in oxen ${ }^{23}$ and in ruminants. ${ }^{36}$ However, the two foramina are separate in tigers, ${ }^{18}$ and in dogs. ${ }^{21}$

The single ethmoidal foramen was present between the nasal and cranial cavities in the lions, similar to what has 


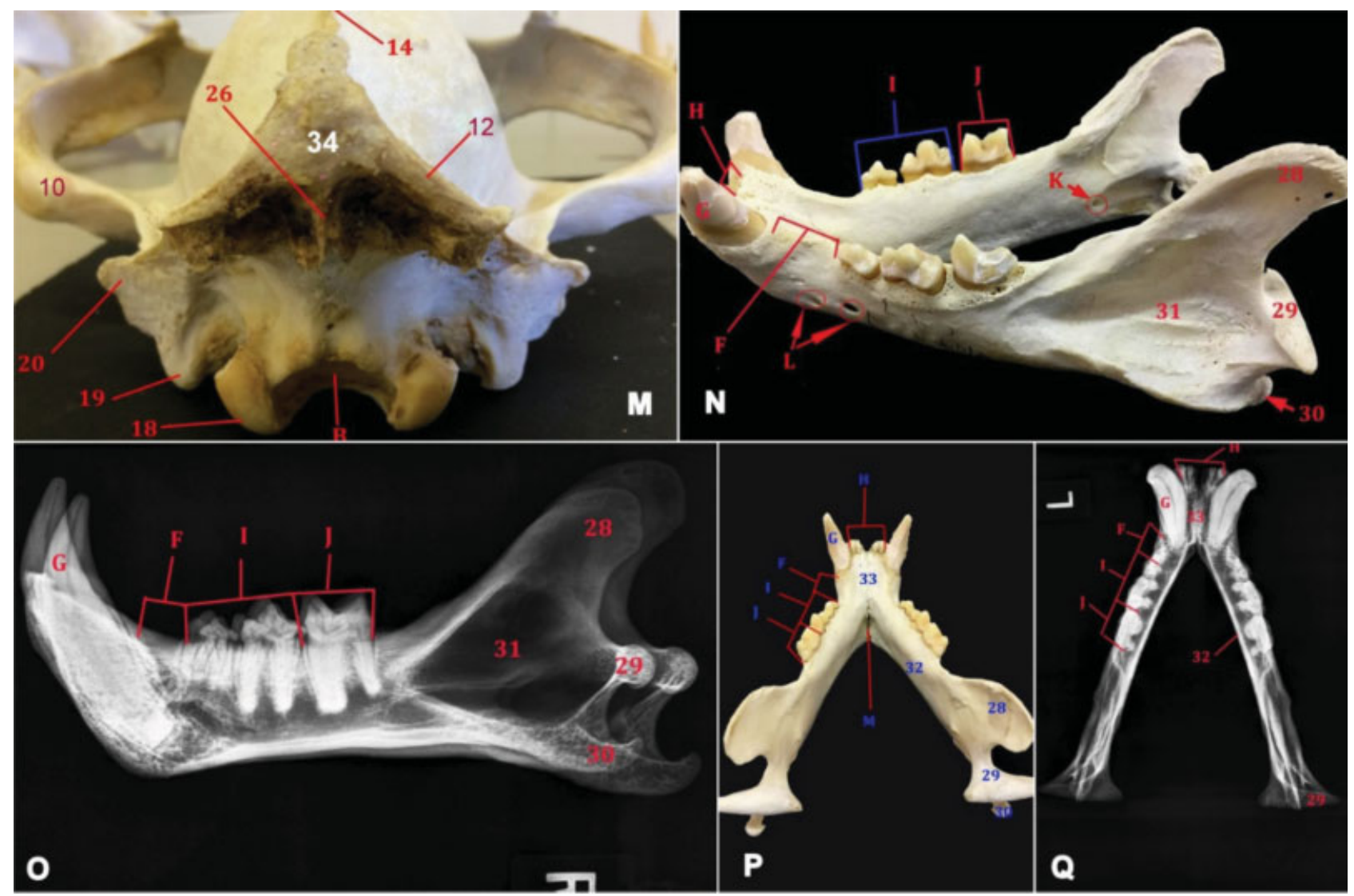

Fig. 4 Gross and radiographic images showing the caudal aspect of the skull (M) and the mandible (N-Q) of the African lion. 10-Zygomatic process of temporal bone; 12-Nuchal crest; 14- External sagittal crest; 18-Occipital condyle; 19-Jugular process; 20-Mastoid process; 26-External occipital crest; 28-Coronoid process; 29-Condylar process; 30-Angular process; 31-Masseteric fossa; 32-Ramus of the mandible; 33-Body of the mandible; 34-External occipital protuberance; B-Foramen magnum; G-Lower canine; F-Diastema; H-Lower incisors; I-Lower premolars; J-Lower molar; K-Mandibular foramen; L-Mental foramina; M-mandibular symphysis.

been reported in horses, ${ }^{19}$ blackbucks, ${ }^{20}$ and in oxen ${ }^{23}$ and yaks. ${ }^{37}$ However, dogs have two ethmoidal foramina, ${ }^{21}$ but none has been observed in camels. ${ }^{22}$

The external sagittal crest was thick and prominent in lions; a similar result was mentioned in Felis bengalencis ${ }^{26}$ and in foxes, ${ }^{38}$ while it is not prominent in brown bears. ${ }^{25}$ Moreover, the zygomatic process of frontal bone is short, as mentioned in brown bears, ${ }^{25}$ while it is long in cats. ${ }^{39}$ Furthermore, the median occipital crest was thick and prominent in lions, while it is not present or not prominent in brown bears, ${ }^{25}$ and in other carnivorous animals. ${ }^{39}$ The jugular processes of the lion were small, similar to what has been observed in dogs, ${ }^{21}$ brown bears ${ }^{25}$ and tigers, ${ }^{31}$ while it is long in foxes..$^{38}$ The tympanic bulla of the lion was large, similar to what has been observed in blackbucks, ${ }^{20}$ oxen, ${ }^{23}$ dogs, ${ }^{21}$ tigers, ${ }^{31} \mathrm{~F}$. bengalencis, ${ }^{26}$ and camels, ${ }^{22}$ while it is small in brown bears, ${ }^{27}$ and in horses. ${ }^{35}$

No particular tubercle was observed in the lion, as mentioned in tigers, ${ }^{18}$ blackbucks, ${ }^{20}$ and dogs, ${ }^{21}$ while it is indistinct in ruminants. ${ }^{36}$ The mastoid process was seen as a small nodule in the lion; a similar result was mentioned in tigers, ${ }^{18}$ while it is absent in blackbucks, ${ }^{20}$ and in camels. ${ }^{22}$ However, it is seen only as a roughened area in small ruminants. ${ }^{35}$ On the other hand, it is well developed in dogs, ${ }^{21}$ in brown bears, ${ }^{25}$ in horses ${ }^{35}$ and in wild cats. ${ }^{38}$
The mandibular symphysis in the lion was not ossified; a similar result was mentioned in blackbucks, ${ }^{20} \mathrm{dogs},{ }^{21}$ and in oxen, ${ }^{23}$ spotted deers ${ }^{40}$ and in tigers. ${ }^{41}$ However, it is completely ossified in horses, ${ }^{19}$ and in camels. ${ }^{22}$

In the mandible, the horizontal part of its ramus was curved slightly, so that it did not make full contact when placed on a flat surface; the incisive part curving upward away of the body remain lifted from the ground; a similar result was recorded in blackbucks, ${ }^{20}$ oxen ${ }^{23}$ and in camels. ${ }^{22}$ However, the horizontal part of the ramus of the mandible of the tiger is straight, and it touches the surface at both sides when it is placed on a flat surface in tigers. ${ }^{18}$ Moreover, the masseteric fossa was strongly excavated, with a well-developed crest, indicating powerful mandibular adduction in lions, ${ }^{28}$ while it has no depression in brown bears, ${ }^{25}$ and in tigers. ${ }^{41}$

The dorsal border of the body of the mandible of the lion housed the dental alveoli for three lower incisors and one lower canine on each side; a similar result was mentioned in bears, lions, ${ }^{1}$ tigers, ${ }^{18}$ blackbucks ${ }^{20}$ and in leopards. ${ }^{42}$ Moreover, the molar part of the body housed the dental alveoli, two premolars, and one molar in the lion, as mentioned in lions and bears, ${ }^{1}$ while it housed three premolar teeth and three molar teeth in horses, ${ }^{19}$ blackbucks, ${ }^{20}$ and in oxen, ${ }^{23}$ yaks ${ }^{43}$ and in leopards. ${ }^{44}$ There were two mental foramina on the lateral surface of the ramus; a similar result was mentioned in 
leopards. ${ }^{42}$ However, there is one foramen in horses, ${ }^{19}$ in blackbucks, ${ }^{20}$ in oxen ${ }^{23}$ spotted deers, ${ }^{40}$ yaks, ${ }^{45}$ and in rhinoceros. ${ }^{46}$ On the other hand, there are three foramina in tigers, ${ }^{18}$ in dogs, $^{19}$ and in camels, ${ }^{22}$ while, there are 2 to 3 mental foramina in tigers. ${ }^{41}$

\section{Conclusion}

The current gross morphological and radiographic study showed that the bones and foramina of the skull and mandible of the African lion were quite similar to those of other mammals. The information obtained from the current study is important for academic information, taxonomic affiliation, wildlife forensic, and to help the zoo veterinarians to manage clinical head diseases in this species.

\section{Conflicts of Interest}

The author declares that they have no conflicts of interest.

\section{Acknowledgments}

The author acknowledges the technical assistance of the basic veterinary sciences department.

\section{References}

1 Alexandra B, Alexandru G, Irina I, et al. Studies regarding comparative aspects of the splanhocranium in the brown bear (ursus arctros) and lion (panthera Leo). Bulletin UASVM. Vet Med 2013; 70(01):7-15

2 Riggio J, Jacobson A, Dollar L, et al. The size of savannah Africa: a lion's (Panthera Leo) view. Biodivers Conserv 2013;22:17-35

3 Bauer $\mathrm{H}$, van der Merwe S. Inventory of free-ranging lions Panthera Leo in Africa. Oryx 2004;38:26-31

4 Baker JR, Lyon DG. Skull malformation and cerebellar herniation in captive African lions. Vet Rec 1977;100(08):154-156

5 Bartsch RC, Imes GD Jr, Smit JPJ. Vitamin A deficiency in the captive African lion cub Panthera loe (Linnaeus, 1758). Onderstepoort J Vet Res 1975;42(02):43-54

6 O'Sullivan BM, Mayo FD, Hartley WJ. Neurologic lesions in young captive lions associated with vitamin A deficiency. Aust Vet J 1977;53(04):187-189

7 Chandra AMS, Papendick RE, Schumacher J, Homer BL, Wollenman P. Cerebellar herniation in captive lions (Panthera leo). J Vet Diagn Invest 1999;11(05):465-468

8 Shamir MH, Horowitz IH, Yakobson B, Ofri R. Arnold-Chiari malformation in a captive African lion cub. J Wildl Dis 1998;34 (03):661-666

9 Dyce KM, Sack WO, Wensing CJG. Text Book of Veterinary Anatomy. St Louis: Elsevier Saunders; 2010

10 Künzel W, Breit S, Oppel M. Morphometric investigations of breedspecific features in feline skulls and considerations on their functional implications. Anat Histol Embryol 2003;32(04):218-223

11 Brüenner H, Lugon-Moulin N, Balloux F, et al. A taxonomical reevaluation of the Valais chromosome race of the common shrew Sorex araneus (Insectivora: Soricidae). Acta Theriol (Warsz) 2002; 47:245-275

12 Yahaya A, Olopade JO, Kwari HD. Morphological analysis and osteometry of the foramen magnum of the one-humped camel (Camelus dromedarius). Anat Histol Embryol 2013;42(02):155-159

13 Rogers TL. Determining the sex of human remains through cranial morphology. J Forensic Sci 2005;50(03):493-500

14 Janeczek M, Chrószcz A, Czerski A. Morphological investigations of the occipital area in adult American Staffordshire Terriers. Anat Histol Embryol 2011;40(04):278-282
15 Cagle L. Concurrent occipital hypoplasia, occipital dysplasia, syringohydromyelia, and hydrocephalus in a Yorkshire terrier. Can Vet J 2010;51(08):904-908

16 Hildebrand M. Anatomical Preparations. Berkely, CA, USA; Los Angeles, CA, USA: University of California Press; 1968

17 International Committee on Veterinary Gross Anatomical Nomenclature. Nomina Anatomica Veterinária, 5th ed. Knoxville, TN, USA: World Association on Veterinary Anatomist; 2012

18 Joshi H. Gross Anatomical Studies of the Skull of Indian Tiger (Panthera tigris). M.V.Sc. thesis, Bikaner, Rajasthan Agricultural University; 2004

19 Getty R. Sisson and Grossman's: The Anatomy of the Domestic Animals, 5th edition, Volume 1. Philadelphia: WB Saunders; 1975

20 Choudhary OP, Singh I. Morphological and radiographic studies on the skull of Indian blackbuck (Antilope cervicapra). Int J Morphol 2016;34:775-783

21 Miller ME, Christensen GC, Evans HE. Anatomy of the dog. Philadelphia: W. B. Saunders Co; 1964

22 Singh P. Gross Anatomical Studies on the Skull of Camel (Camelus dromedarius). M.V.Sc. thesis, Hisar, Haryana Agriculture University; 1984

23 Raghavan D. Anatomy of the Ox; with Comparative Notes on the Horse, Dog and Fowl. New Delhi: Indian Council of Agricultural Research; 1964

24 Williams VL, Loveridge AJ, Newton DJ, et al. Skullduggery: Lions align and their mandibular rock. PLoS One 2015;10:1-5

25 Yousefi MH. Anatomical study of the Iranian brown bear's skull (Ursus arctos): A case report. Iran J Vet Med 2016;10:237-244

26 Sarma K, Nashiruddullah N, Islam S, et al. Anatomy of the skull of a leopard cat (Felis bengalensis). Indian J Anim Sci 2001;71:1011-1013

27 Archana DN Sharma, Kishtwaria RS, et al. Anatomy of skull of sambar deer. (Census unicolor). XVIII IAVA Convention Souvenir and Abstracts, 26-28th December 2003. Gujarat Agricultural University, Anand Campus, Anand 2003

28 Mazák JH, Christiansen P, Kitchener AC. Oldest known pantherine skull and evolution of the tiger. PLoS One 2011;6(10):e25483

29 Borthakur S, Bordoloi CC. Gross anatomical study on the skull of adult rhino (Rhinocerous unicornis). Indian J Vet Anat 1997; 74:670-672

30 Shahid RU, Kausar R. Comparative gross anatomical studies of the skull of one-humped camel (Camelus dromedarius). Pak Vet J 2005;25:205-206

31 Pandey Y, Vaish R, Pandey A, et al. Gross morphometrical studies on cranial bones in tiger. Bioscan 2017;12:811-814

32 Kalita PC, Kalita HC, Sarma K, et al. Anatomy of the skull of sloth bear (Melursus ursinus). Indian J Anim Sci 2006;76:225-227

33 Zuoliang F. Comparative anatomical studies on the skeleton of arctic foxes. Journal of Economic Animal 2004;8:80-84

34 Mohamed R. Anatomical and Radiographic Study on the Skull and Mandible of the Common Opossum (Didelphis Marsupialis Linnaeus, 1758) in the Caribbean. Vet Sci 2018;5(02):1-10

35 Nickel R, Schummer A, Seiferle E. The Anatomy of the Domestic Animals. Vol. 1: The Locomotor System. Verlag Paul Parey. Berlin and Hamburg, Germany: Springer Verlag; 1986

36 Sisson S. Ruminant Osteology. In: Sisson S, Grossman JD, Getty R. (Eds.). Sisson and Grossman's The Anatomy of the Domestic Animals. 5th ed. Philadelphia: W. B. Saunder's Co; 1964

37 Archana, Sudhakar LS, Sharma DN, et al. Anatomy of the ethmoid bone of yak (Bos grunniens). Indian Journal of Veterinary Anatomy 1998a10:21-5

38 Atalar O, Ustundag Y, Yaman M, et al. Comparative anatomy of the neuro-cranium in some wild carnivore. J Anim Vet Adv 2009; 8:1542-1544

39 Evans HE, Christensen GC. Anatomy of the Dog. Publ. Philadelphia: W.B. Saunders Co; 1964:147

40 Kumawat R, Joshi S, Mathur R, et al. Gross anatomical studies on the cranial bones of skull in chital (Axis axis). Indian J Vet Anat 2014;26:54-55 
41 Tiwari Y, Taluja JS, Vaish R, et al. Biometry of mandible in tiger (Panthera tigris). Annual Review \& Research in Biology 2011; 1:14-21

42 Ray S, Dutta GKM, Ray M, et al. Anatomy of the mandible of leopard (Panthera pardus). Indian Vet J 1997;74:765-767

43 Archana, Sudhakar LS, Sharma DN, et al. Anatomy of the parietal and interparietal bones of ak (Bos grunniens). Indian Journal of Veterinary Anatomy 1998c10:26-30
44 Sarma K, Sarma M, Nashirudullah N, et al. Anatomy of the mandible of leopard cat (Felis bengalancis). Indian Vet J 2002;79:1063-1064

45 Archana, Sudhakar LS, Sharma DN, et al. Anatomy of the mandible of yak (Bos grunniens). Indian Journal of Veterinary Anatomy 1998b10:16-20

46 Bordoloi CC, Borthakur S, Talukdar SR, et al. Mandible of the great Indian one-horned rhinoceros (Rhinoceros unicornis). Indian J Vet Anat $1995 ; 72: 838-842$ 